\title{
Increasing Transparency through Web Maps
}

\author{
Auriol Degbelo \\ Institute for Geoinformatics, University of Münster \\ Münster, Germany \\ degbelo@uni-muenster.de
}

\author{
Tomi Kauppinen \\ Aalto University School of Science \\ Helsinki, Finland \\ tomi.kauppinen@aalto.fi
}

\begin{abstract}
Recent years have witnessed progress of public institutions in making their datasets available online, free of charge, for re-use. This notwithstanding, there is still a long way to go to put the power of data in the hands of citizens. This article suggests that transparency in the context of open government can be increased through web maps featuring: i) Application Programming Interfaces (APIs) which support app and data usage tracking; and (ii) 'transparency badges' which inform the users about the presence/absence of extra, useful contextual information. Eight examples of web maps are introduced as proof of concept for the idea. Designing and implementing these web maps has reminded of the need of interactive guidelines to help non-experts select vocabularies, and datasets to link to. The ideas presented are relevant to making existing open data more user friendly (and ultimately more usable).
\end{abstract}

\section{CCS CONCEPTS}

- Human-centered computing $\rightarrow$ Geographic visualization; Visualization systems and tools;

\section{KEYWORDS}

Transparency, Web Maps, Open Geodata, Visual Variables, Cartographic Interaction Primitives, Linked Data Visualization

\section{ACM Reference Format:}

Auriol Degbelo and Tomi Kauppinen. 2018. Increasing Transparency through Web Maps. In WWW'18 Companion: The 2018 Web Conference Companion, April 23-27, 2018, Lyon, France. ACM, New York, NY, USA, 6 pages. https://doi.org/10.1145/3184558.3191515

\section{INTRODUCTION}

The topic of smart cities has attracted growing interest from research, industry and local governments. Many definitions exist (for a review, see [25]), reflecting the plurality of perspectives in the context. Within this article, smart city is defined after [25] as "a systematic integration of technological infrastructures that relies on advanced data processing, with the goals of making city governance more efficient, citizens happier, businesses more prosperous and the environment more sustainable". Citizen participation (i.e., getting citizens to timely voice their opinions and wishes) is a key aspect of making city governance more efficient and citizens happier. Indeed, as Milakovich [19] noted, "Citizen participation provides a source of special insight, information, knowledge, and experience, which

This paper is published under the Creative Commons Attribution 4.0 International (CC BY 4.0) license. Authors reserve their rights to disseminate the work on their personal and corporate Web sites with the appropriate attribution.

WWW'18 Companion, April 23-27, 2018, Lyon, France

() 2018 IW3C2 (International World Wide Web Conference Committee), published under Creative Commons CC BY 4.0 License.

ACM ISBN 978-1-4503-5640-4/18/04.

https://doi.org/10.1145/3184558.3191515 contributes to the soundness of government solutions to public problems". Improved citizen participation, in turn, requires greater transparency as citizens must know (or be made known) what is happening in their city and how they can best contribute to it, in order to effectively participate. There are several dimensions of transparency discussed in [14], but in this work we focus on what Johannessen and Berntzen [14] called benchmarking transparency, i.e., the availability of open data (e.g., results from user surveys, demographic information), which citizens and interested parties can use to get a better idea of what is happening within government entities.

Despite a greater availability of open datasets, there is, as the second edition of the Open Data Barometer pointed out "still a long way to go to put the power of data in the hands of citizens" (http://opendatabarometer.org/2ndEdition/, last accessed: January 31,2018 ). Visualising or geovisualizing open data seems the next logical step to put open data in the hands of citizens. Brunetti et al. [6] formalised the whole process of getting from a raw dataset to a visualisation as a framework called the Linked Data Visualisation Model (LDVM). LODVisualization [6] and LinkedPipes Visualisation [16] are two examples of tools which support LDVM. The current work differs from these two in mainly two ways: (i) a deliberate focus on geographic data preparation, visualisation and interaction (while the two works aforementioned take a more generic approach towards visualisation of open data on the web); and (ii) an account for the transformation from non-RDF data sources to RDF (which the two other tools did not intend to address). The main contributions of this paper are twofold.

First, we present a set of web maps to enable greater transparency in society. These web maps are part the Open City Toolkit, described in [10] as a platform to "to deliver services based on open data that are useful for citizens, businesses and governing bodies alike". As such, they are one way of realising Dadzie and Pietriga's aspiration (regarding work on Linked Data visualisation) expressed as follows: We look forward to a growing library of shared knowledge and visualisation-driven tools that break down technological barriers, promoting instead richer exploration and intuitive, insightful analysis of users' personal context, myriad, shared situations and complex problems captured in Linked Data, and enable end users to draw confident conclusions about data and situations and add value to their everyday, knowledge driven tasks ([8], emphasis added). All the web maps focus primarily on the presentation of the information, essentially hiding the technicalities of Linked Data (e.g., RDF Syntax) to the users. Second, the paper provides a critical analysis of these tools using concepts from cartographic representation and interaction. The analysis produces intrinsic, descriptive knowledge about the web maps (with no claim of generalisability to all web maps), and ends with some lessons learned about representation and interaction with geographic data on the web. In addition, as 
Çöltekin et al. [7] recently reminded, "we do not know enough about in which domains geovisualization can be (potentially) of use". The set of web maps provided are artefacts illustrating one possible application domain of geovisualisations, namely enabling greater transparency in the society.

\section{BACKGROUND}

Kamaruddin and Md Noor [15] identified four components of citizencentricity which are used as a starting point in this paper (i.e., openness, transparency, responsiveness and participation). In line with [18], transparency is viewed here as having two dimensions: visibility and inferability. The visibility dimension refers to the extent to which information is complete and easily located; the inferability dimension points to the degree to which information can be used to draw accurate conclusions. Conceptually, a map can be viewed as a geometric structure [20], a graphical image [20] or a set of statements made by an author at a point in time [9]. Taking the viewpoint of maps as statements as a starting point, web maps are helpful to enable greater transparency in that they can make value more visible and inferable. Value of what? Of activities, processes and products pertaining to the public sphere. Why value? Because getting and keeping citizens interested in the participating in public decisions relies upon an appropriate communication of the value of their participation. Value, as used here, is in line with Benington [2]'s definition of 'public value', and encompasses "ecological, political, social, and cultural dimensions of value" (or simply said, all that adds value to the public sphere). The remainder of the article will not discuss all possible (and numerous) dimensions of values in the context of public sphere. Instead, it focuses on web maps which enable greater transparency by making the value of open (government) data more visible and inferable. Value of open data has many dimensions (i.e., technical, economical, social, cultural, and political) which were discussed in [1]. The value creation assessment framework of [1] lists no less than 19 (mostly technical) aspects which should be considered when evaluating the potential of an open government data initiative to enable value creation. Three of these 19 aspects were addressed in the current work:

- Data usability: datasets in formats such as Comma Separated Values (CSV), Portable Document Format (PDF) or Resource Description Framework (RDF) are not necessarily citizen-friendly. Visualising them is a way of adding to their value;

- Background context: linking datasets to related datasets (or simply making more specific their semantics through a conversion into RDF) does add value to existing datasets;

- Rate of reuse: providing information about the re-use rate of some datasets is a way of unveiling their actual social value.

The next section presents a set of web maps adding value to existing open datasets by realising these three aspects.

\section{RESEARCH APPROACH}

This work follows a two-step approach. In the first step, a set of web maps built to enable greater transparency in society are presented, along with the technical features needed to implement them. In the second step, these web maps are critically analysed to bring forth visual variables and interaction primitives relevant for maps enabling greater transparency.

\subsection{Generating the web maps}

As mentioned above, the main purpose of the web maps is to enable greater transparency in society. As discussed in [9], two techniques are particularly suitable for this goal, namely Linked Data and visualisation. Linked Data increases transparency for machines, and visualisations do so for humans. To increase transparency, $36 \mathrm{stu}-$ dents (divided into groups of three to six members) were asked to take existing open data, transform it into linked open data, and geovisualise it. The students were part of two classes organized in a blended learning fashion at two consequent years (one class took place with 19 people in the Winter term 2015/2017, and the second took place with 17 people in the Winter term 2016/2017). In the first class, open data from Münster was used as raw data; in the second class, participants were asked to work with open data of their choice. They were all non-familiar with Linked Data, and had various degrees of familiarity with web technologies (like HTML5, CSS, JavaScript or Node.js). The apps based on existing open data, and built as part of the practical work within the classes are: Crime Mapper (A1): a web app for citizens \& tourists to get a better overview of the crimes in Greater London; Münster Households (A2): an interactive map for citizens \& city councils to see households data from Münster between 2010 and 2014; Münster Migration (A3): an interactive map for citizens \& city councils to go through migration statistics from Münster between 2010 and 2014; Münster Population (A4): an interactive map for citizens \& city councils to browse population data from Münster between 2010 and 2014; Münster Social Insurance (A5): an interactive map for citizens \& city councils to get an idea about the number of employees subject to social insurance contributions in Münster between 2010 and 2014; Münster Unemployment (A6): an interactive map for citizens \& city councils to explore unemployment data from Münster between 2010 and 2014; Referendum Map Münster (A7): an interactive map for citizens \& city councils to see results of the 2016 referendum regarding opening shops in the Münster city center; and Wildlife Columbia (A8): a web app for policy makers \& researchers to see information about protected natural reserves in Columbia, and species that inhabit these reserves.

Besides increasing data usability and providing background context about the datasets intrinsically, a novel feature of the web maps is the provision of information of the rate of open data usage. Technically, all web maps use the semantic API from [11] which enables app and dataset usage tracking, resulting in greater transparency. Degbelo et al. [11] suggested that APIs which return data items according to their types - what they called semantic APIs - would lead to greater transparency (for developers) in an open government context, and identified recurrent categories of open datasets based on a survey of 40 European open data catalogues. Each of the web maps using the semantic API gets a 'transparency badge' (see Figure 1, bottom left corner), which indicates their support for dataset usage tracking. By clicking on this badge, the user is redirected to a dashboard-like platform which provides information about all applications available, the open datasets needed for their functioning, and their access rates of these datasets (see Figure 2). The information potential of users regarding what is happening with open datasets (i.e., how these are used in one or many apps) is thereby increased. One can also visualise most demanded datasets 
using the 'Datasets' tab (see Figure 2). The transparency badge is mainly useful here to inform about rate of dataset usage. Yet, its conceptual scope should not be limited to this. One could envision further useful information provided to citizens after a click on a transparency badge. Example of relevant information in the context of open data visualisation include (the list is far from exhaustive):

- source datasets of the visualisation: according to the survey from [12], this is a most desired information by participants;

- trustworthiness of the visualisation, and of the dataset: as Tim Berners Lee recently reminded [5] "It's too easy for misinformation to spread on the web". The transparency badge could, for example, say whether the data (and/or its visualisation) has been verified by a public institution;

- hints about data completeness: participants from [4] mentioned data incompleteness as one of the most severe barriers to open data adoption. Informing about data completeness may not solve the issue, but is already a way forward;

- hints about data currency: the lack of updates of published open data appears at the top of the list of participants from [3] when it comes to major barriers to open data re-use. Here also, informing about data updating policies does not solve the issue, but can, at least, help citizens know what to expect;

- licensing information about the dataset, and the visualisation: this is mostly relevant to developers interested in re-use;

- purpose of the data and the visualisation: why the dataset has been collected, and why the visualisation has been created;

- adoption examples: how the dataset has been adopted elsewhere, and how it has been used in that (or these) scenario.

The final list of the transparency badge's informational items may be decided by its provider. This being said, experience from the food industry (where nutrition facts labels for packaged foods have proven simple and informative to consumers) suggests that standardisation of the informational items of a transparency badge (e.g., through the $\mathrm{W} 3 \mathrm{C}$ ) could be helpful for the web as a whole at some point. The source codes of all web maps is available on GitHub (https://github.com/geo-c). Short demos can be accessed on Youtube (https://goo.gl/73nxvv). The apps were built using open source technologies. Examples of libraries used include Leaflet (open source map), Bootstrap (responsive web design), HighCharts, Charts.js, D3.js, C3.js and CanvasJS (histograms generation), Chroma.js (colour manipulation), and IntroJS (short intro to the main functionalities). Parliament and Virtuoso were used as triple stores. Vocabularies used while producing the RDF datasets include: geosparql (http: //www.opengis.net/ont/geosparql), dc (http://purl.org/dc/elements/ 1.1/), dbpedia-ont (http://dbpedia.org/ontology/), geonames (http: //www.geonames.org/ontology/), geo (https://www.w3.org/2003/ 01/geo/), time (www.w3.org/2006/time\#) and datacube (https:// www.w3.org/TR/vocab-data-cube/), to name but a few. Custom terms were created per application domain (i.e., population, migration, referendum, and so forth) to meet their respective needs.

\subsection{Analysis}

There are many dimensions along which the maps could be analysed. Since all maps are Linked Data visualisations, the dimensions presented in [8] are a possible choice. However, since little is known on how geovisualisations apply to different domains (see Section
1), the work instead adopted a framework for analysis which will help see how theoretical concepts from interactive maps have beenf applied to the task of enabling greater transparency. Of particular relevance are the concepts of 'visual variables' summarised in [22], and of 'interaction operators' from [21].

Visual variables are one basic building block of a map or a visualisation. They describe "the graphic dimensions across which a map or other visualization can be varied to encode information" [22]. Many visual variables were suggested over the course of the years, and Roth [22] synthesised them into a list of 12: location (i.e., position of a map symbol with respect to a coordinate frame); size (i.e., amount of space occupied by a map symbol); shape (i.e., outline of the map symbol); orientation (i.e., rotation of the map symbol from "normal"); colour hue (i.e., dominant wavelength of the map symbol on the visible spectrum); colour value (i.e., relative amount of energy emitted or reflected by the map symbol); texture (i.e., coarseness of the fill pattern within the map symbol); colour saturation (i.e., intensity of the colour of the map symbol); arrangement (i.e., layout of graphic marks constituting a symbol); crispness (i.e., sharpness of the boundary of the map symbol); resolution (i.e., spatial precision at which the map symbol is displayed), and transparency (i.e., amount of graphic blending between a map symbol and underlying map symbols).

Next to visual variables, interaction primitives are another basic building block of a map. Roth [21] brought forth an empiricallyderived taxonomy of interaction primitives. According to this taxonomy, there are three primitive interaction goals (procure, predict, and prescribe), and five primitive interaction objectives (identify, compare, rank, associate, and delineate). In addition, the taxonomy comes up with a distinction between enabling interaction operators (import, export, save, edit, and annotate) and work interaction operators (reexpress, arrange, sequence, resymbolize, overlay, reproject, pan, zoom, filter, search, retrieve, and calculate). Work operators accomplish the desired objective, while enabling operators are useful to prepare for (or clean up) from work operators. Finally, the taxonomy lists three types of interaction operands related to the search target (space-alone, attributes-in-space, and space-in-time). There are two further interaction operands related to the search level (elementary and general). The reader is referred to [21] for a full description of the taxonomy. The assessment of the web maps using this taxonomy is summarized in Table 1 . The broad interaction goal enabled by all web maps is procure (i.e., enable retrieval of information about a geographic phenomenon represented, as opposed to make predictions about future states of the phenomenon at hand). Apart from A3 which proposes interaction to export data, none of the apps used enabling operators. The visual variable of colour saturation was left out of the analysis, because assessing it with the human eye is error-prone.

\section{DISCUSSION}

This section briefly presents lessons learned from the building process, and subsequent analysis of the web maps.

Lessons learned on visual variables: of the 12 visual variables listed in [22], colour is the only one which has recurrently been used across the various web maps. This reminds that effective colour 


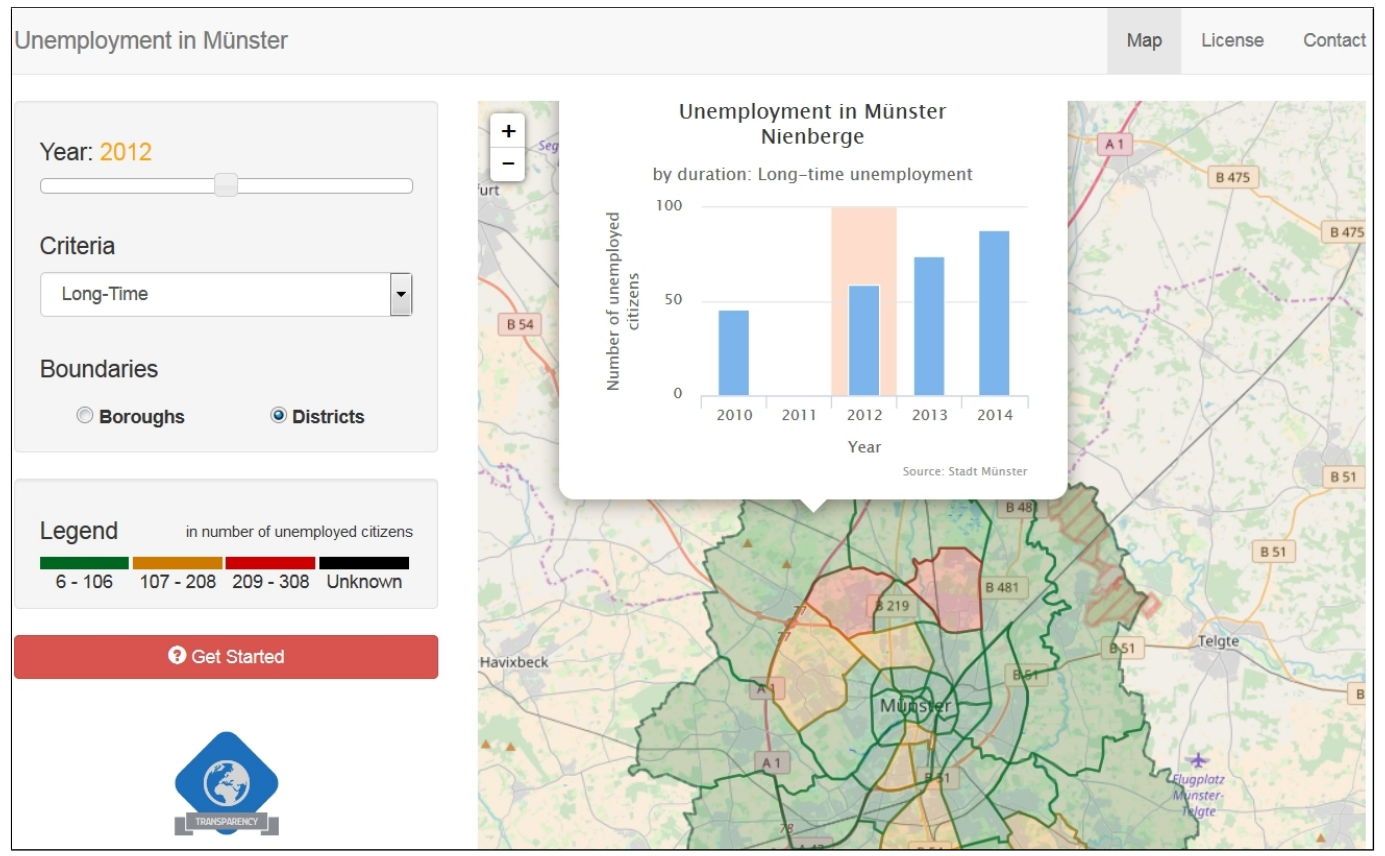

Figure 1: Münster Unemployment - Application with visualises open data from Münster as a web map. The transparency badge signals greater transparency support (i.e., the presence of extra, useful contextual information) for users of the visualisation.

Table 1: Features of the web maps*

\begin{tabular}{|c|c|c|c|c|c|c|}
\hline & NT & $\mathrm{NV}(\mathrm{CV})$ & Open Dataset Used & Visual Variables & Operands // Objectives Supported & Work Operators \\
\hline A1 & 485,331 & $10(1)$ & crime data & colour hue & $\begin{array}{l}\text { space-alone, attribute-in-space, } \\
\text { space-in-time // identify }\end{array}$ & $\begin{array}{l}\text { pan, zoom, retrieve, resym- } \\
\text { bolize, overlay, calculate }\end{array}$ \\
\hline A2 & 31,162 & $21(1)$ & households count data & $\begin{array}{l}\text { colour hue, } \\
\text { colour value }\end{array}$ & $\begin{array}{l}\text { space-alone, attribute-in-space, } \\
\text { space-in-time // identify }\end{array}$ & pan, zoom, retrieve \\
\hline A3 & 1,391 & $4(1)$ & mig1 & - & $\begin{array}{l}\text { space-alone, attribute-in-space, } \\
\text { space-in-time // identify }\end{array}$ & $\begin{array}{l}\text { pan, zoom, retrieve, resym- } \\
\text { bolize, overlay }\end{array}$ \\
\hline A4 & 6,668 & $9(1)$ & popu & $\begin{array}{l}\text { colour hue, } \\
\text { colour value }\end{array}$ & $\begin{array}{l}\text { space-alone, attribute-in-space, } \\
\text { space-in-time // identify, compare }\end{array}$ & $\begin{array}{l}\text { pan, zoom, retrieve, resym- } \\
\text { bolize, overlay, calculate }\end{array}$ \\
\hline A5 & 1,869 & $8(1)$ & $\begin{array}{l}\text { social insurance contri- } \\
\text { bution data }\end{array}$ & colour value & $\begin{array}{l}\text { space-alone, attribute-in-space, } \\
\text { space-in-time // identify, compare }\end{array}$ & pan, zoom, retrieve, calculate \\
\hline A6 & 4,399 & $6(1)$ & unemployment data & colour hue & $\begin{array}{l}\text { space-alone, attribute-in-space, } \\
\text { space-in-time // identify }\end{array}$ & pan, zoom, retriev \\
\hline A7 & 1,327 & $5(1)$ & election data & colour hue & $\begin{array}{l}\text { space-alone, attribute-in-space // } \\
\text { identify }\end{array}$ & pan, zoom, retrieve, overlay \\
\hline A8 & 2,432 & $16(1)$ & $\begin{array}{l}\text { endangered species } \\
\text { data, deforestation } \\
\text { data, social index data }\end{array}$ & colour hue & $\begin{array}{l}\text { space-alone, attribute-in-space // } \\
\text { identify }\end{array}$ & $\begin{array}{l}\text { pan, zoom, retrieve, resym- } \\
\text { bolize, overlay, search }\end{array}$ \\
\hline
\end{tabular}

*Table Legend - NT: Number of triples; NV: Number of vocabularies used; CV: Custom vocabulary.

selection will be key in enabling greater citizen-centricity on the web. ColorBrewer.org [13] was a tool proposed in the early $2000 \mathrm{~s}$ to help map makers choose effective colour schemes for thematic maps. Though it was tested for a variety of display types (e.g., LCD, CRT) and widely used, the emergence of new display types (e.g., AMOLED or Retina) suggests the need for new brewers which take into account advances in cartographic research, displays types and colour theory to assist developers in selecting most effective colour schemes while making their maps.

Lessons learned on interaction primitives: the question of how to best systematically document (Linked Data) visualisations in the 


\begin{tabular}{|c|c|c|c|c|c|}
\hline Apps & Categories & Usage & & & $\Rightarrow$ Register \\
\hline More & Name & Description & Category Search 9 & Dataset Search 9 & App Type \\
\hline & Münster Migration & $\begin{array}{l}\text { Visualization of } \\
\text { migration statistics from } \\
\text { Münster }\end{array}$ & 1 & 18 & WebApp \\
\hline & Münster Households & $\begin{array}{l}\text { Map of households data } \\
\text { from Münster }\end{array}$ & 2 & 163 & WebApp \\
\hline & Crime Mapper & $\begin{array}{l}\text { Mapping crimes of } \\
\text { Greater London }\end{array}$ & 1 & 48 & WebApp \\
\hline & $\begin{array}{l}\text { Münster } \\
\text { Sociallnsurance }\end{array}$ & $\begin{array}{l}\text { Employees subject to } \\
\text { social insurance } \\
\text { contributions in Münster }\end{array}$ & 2 & 26 & WebApp \\
\hline & Münster Population & $\begin{array}{l}\text { Map of population data } \\
\text { from Münster }\end{array}$ & 1 & 57 & WebApp \\
\hline & Wildlife Columbia & $\begin{array}{l}\text { Mapping natural } \\
\text { reserves in Columbia }\end{array}$ & 1 & 37 & WebApp \\
\hline & $\begin{array}{l}\text { Referendum Map } \\
\text { Münster }\end{array}$ & $\begin{array}{l}\text { Mapping referendum } \\
\text { data from Münster }\end{array}$ & 1 & 152 & WebApp \\
\hline & Münster Unemployment & $\begin{array}{l}\text { Visualization of } \\
\text { unemployment data } \\
\text { from Münster }\end{array}$ & 1 & 39 & WebApp \\
\hline
\end{tabular}

Figure 2: Dashboard-like visualisation of available applications as well as their access rates to existing applications.

context of the Semantic Web is important, but still open. In essence, this systematic documentation is important to synthesise gained knowledge across various visualisations (and use cases). As discussed in Section 3, the dimensions used in [8] (which were derived from general visualisation design guidelines and best practices) are an option. This work chose instead Roth [21]'s taxonomy of interaction primitives, which is specific to map interaction, and was derived from an empirical study. The taxonomy has proven quite usable while characterising the maps. This taxonomy may also be used in the future to stress interaction aspects of map visualisations on the web. The main lesson learned is that finding a definite answer to the question how does objective restricts the space of possible map interaction operators on the Web? might need a further specialisation of the objective primitives from Roth [21] as current primitive terms (e.g., identify, compare) do not lead to a conclusive answer.

Lessons learned on Linked Data vocabularies: Table 1 shows that (perhaps unsurprisingly) all web maps used a custom vocabulary, in addition to existing ones. Though there is an increasing number of vocabularies indexed by LOV [23], having to define one's own terms to fully cover the use case at hand might remain the rule rather than the exception for some time. The process of designing and implementing the eight web maps (Section 3) has reminded that finding datasets other than Dbpedia to link to is still a challenge, and finding vocabularies to re-use remains challenging for non-experts. Interactive guidelines assisting them for the two tasks could help tackle these issues.

The way forward - Enhancing citizen centricity with web maps: as we have argued, citizens can benefit when web maps present diverse phenomena about their surroundings in a comprehensible way. It is possible to make use of a variety of open datasets, often linkable together, to create rich, visually communicated messages as web maps. However, the core value-citizen centricity-is enabled by transparency and openness of the web maps approach. When citizens can take a look at both web maps and their transparency badges, they are at the centre using and benefiting from information. Evidencing the source of used datasets and visualisations, metrics for their trustworthiness and completeness all contribute to creating value well beyond just having open data online. Further, seeing how many other people (including authorities) are interacting with information with the same web maps can support creating trust for information. A data-driven approach 
is not only to inform citizens but can also lead to "citizen-led urban innovations" [24] and create opportunities to react-with evidenceon issues emerging in local communities.

Limitations: though we argue in this paper for the use of web maps to enable greater transparency, it must be admitted that maps have their own learning curve. In fact, each communication medium has its own advantages and disadvantages. For instance, PDF files may be easier to generate from various sources such as text editors, but tables and other structured contents are challenging to parse; CSV or RDF files are machine processable, but without proper information visualization tools challenging to communicate to people. A systematic comparison of these different ways of making datasets available to the wider public (using e.g., the evaluation model from [17]) could help better understand their respective merits in the context of open government.

\section{CONCLUSION AND OUTLOOK}

In this paper we suggested that citizen-centricity of open data initiatives could be increased via web maps. This will make the value of activities, processes and products pertaining to the public sphere more visible. Open data is one of these products. We suggested that web maps featuring 'transparency badges' can be used to make their value more visible, thus increasing transparency. We presented eight example web maps to illustrate the idea, and documented lessons learned while designing and implementing them. An immediate research direction for future work is the understanding of citizens' wishes regarding the information to be provided by transparency badges. Shedding light on this can happen through a large-scale citizen survey, or via partnerships with city councils which have already made their data open. For instance, one could get statistics from city councils regarding actual users of these open datasets, select some of these users via purposive sampling, and interview them to understand what they actually need, and why they need it. Finally, it has become clear during the course of our work that a systematic evaluation of different communication mediums (e.g., when, and for which citizen groups do PDF or web maps perform best regarding information provision?) would be useful to advance citizen-centricity of open data initiatives.

\section{ACKNOWLEDGMENTS}

Auriol Degbelo gratefully acknowledges funding from the European Union through the GEO-C project (H2020-MSCA-ITN-2014, Grant Agreement Number 642332, http://www.geo-c.eu/). Tomi Kauppinen gratefully acknowledges Aalto Online Learning (A!OLE), a strategic initiative of the Aalto University, the project which he serves as a project leader. We thank Jonas Wissing for designing the logo of the transparency badge, and participants of the seminars "An Introduction to Javascript and Linked Data" (WiSe 2015/2016), and "Geoinformation in Society" (WiSe 2016/2017) at the Institute for Geoinformatics, University of Münster for implementing the web maps mentioned in this article.

\section{REFERENCES}

[1] Judie Attard, Fabrizio Orlandi, and Soren Auer. 2016. Value creation on open government data. In 2016 49th Hawaii International Conference on System Sciences. IEEE, Koloa, Hawaii, USA, 2605-2614. https://doi.org/10.1109/HICSS.2016.326
[2] John Benington. 2009. Creating the public in order to create public value? International fournal of Public Administration 32, 3-4 (mar 2009), 232-249. https: //doi.org/10.1080/01900690902749578

[3] Fernando Benitez-Paez, Auriol Degbelo, Sergio Trilles, and Joaquin Huerta. 2018. Roadblocks hindering the reuse of open geodata in Colombia and Spain: a data user's perspective. ISPRS International fournal of Geo-Information 7, 1 (dec 2018), 6. https://doi.org/10.3390/ijgi7010006

[4] Martin Beno, Kathrin Figl, Jurgen Umbrich, and Axel Polleres. 2017. Open data hopes and fears: determining the barriers of open data. In 2017 Conference for EDemocracy and Open Government (CeDEM), Peter Parycek and Noella Edelmann (Eds.). IEEE, Krems, Austria, 69-81. https://doi.org/10.1109/CeDEM.2017.22

[5] Tim Berners-Lee. 2017. Tim Berners-Lee: I invented the web. Here are three things we need to change to save it. (2017). https://www.theguardian.com/ technology/2017/mar/11/tim-berners-lee-web-inventor-save-internet (Last accessed: January 18, 2018).

[6] J.M. Brunetti, S. Auer, and R. García. 2012. The linked data visualization model. In Proceedings of the ISWC 2012 Posters \& Demonstrations Track, Birte Glimm and David Huynh (Eds.). CEUR-WS.org, Boston, Massachusetts, USA.

[7] Arzu Çöltekin, Susanne Bleisch, Gennady Andrienko, and Jason Dykes. 2017. Persistent challenges in geovisualization - a community perspective. Int. fournal of Cartography (apr 2017), 1-25. https://doi.org/10.1080/23729333.2017.1302910

[8] Aba-Sah Dadzie and Emmanuel Pietriga 2017. Visualisation of linked data reprise. Semantic Web 8, 1 (nov 2017), 1-21. https://doi.org/10.3233/SW-160249

[9] Auriol Degbelo. 2017. Linked data and visualization: two sides of the transparency coin. In Proceedings of Urban GIS'17. ACM Press, Los Angeles, California, USA, 1-8. https://doi.org/10.1145/3152178.3152191

[10] Auriol Degbelo, Carlos Granell, Sergio Trilles, Devanjan Bhattacharya, Sven Casteleyn, and Christian Kray. 2016. Opening up smart cities: citizen-centric challenges and opportunities from GIScience. ISPRS International fournal of Geo-Information 5, 2 (2016), 16. https://doi.org/10.3390/ijgi5020016

[11] Auriol Degbelo, Sergio Trilles, Christian Kray, Devanjan Bhattacharya, Nicholas Schiestel, Jonas Wissing, and Carlos Granell. 2016. Designing semantic APIs for open government data. efournal of Democracy (JeDEM) 8, 2 (2016), 21-58.

[12] Alvaro Graves and James Hendler. 2013. Visualization tools for open government data. In Proceedings of the 14th Annual International Conference on Digital Government Research - dg.o '13, Sehl Mellouli, Luis F. Luna-Reyes, and Jing Zhang (Eds.). ACM Press, Quebec, Canada, 136. https://doi.org/10.1145/2479724.2479746

[13] Mark Harrower and Cynthia A. Brewer. 2003. ColorBrewer.org: an online tool for selecting colour schemes for maps. The Cartographic fournal 40, 1 (jun 2003), 27-37. https://doi.org/10.1179/000870403235002042

[14] Marius Rohde Johannessen and Lasse Berntzen. 2018. The transparent smart city. In Smart Technologies for Smart Governments, Manuel Pedro Rodríguez Bolívar (Ed.). Springer, 67-94. https://doi.org/10.1007/978-3-319-58577-2_5

[15] Kamalia Kamaruddin and Nor Laila Md Noor. 2017. Citizen-centric demand model for transformational government systems. In 21st Pacific Asia Conference on Information Systems (PACIS 2017). Langkawi, Malaysia.

[16] Jakub Klímek, Jiří Helmich, and Martin Nečaský. 2016. LinkedPipes visualization: simple useful linked data visualization use cases. In ESWC 2016 Satellite Events -Revised Selected Papers, Harald Sack, Giuseppe Rizzo, Nadine Steinmetz, Dunja Mladenić, Sören Auer, and Christoph Lange (Eds.). Springer, Cham, 112-117. https://doi.org/10.1007/978-3-319-47602-5 23

[17] Lili Wang, S. Bretschneider, and J. Gant. 2005. Evaluating web-based egovernment services with a citizen-centric approach. In Proceedings of the 38th Annual Hawaii International Conference on System Sciences. IEEE Computer Society, Big Island, Hawai, USA, 129b. https://doi.org/10.1109/HICSS.2005.252

[18] G Michener and K Bersch. 2013. Identifying transparency. Information Polity 18, 3 (2013), 233-242. https://doi.org/10.3233/IP-130299

[19] Michael E. Milakovich. 2010. The internet and increased citizen participation in government. efournal of Democracy (feDEM) 2, 1 (2010), 1-9.

[20] Donna J. Peuquet. 1988. Representations of geographic space: toward a conceptual synthesis. Annals of the Association of American Geographers 78, 3 (sep 1988), 375-394. https://doi.org/10.1111/j.1467-8306.1988.tb00214.x

[21] Robert E. Roth. 2013. An empirically-derived taxonomy of interaction primitives for interactive cartography and geovisualization. IEEE Trans. Vis. Comput. Graphics 19, 12 (2013), 2356-2365. https://doi.org/10.1109/TVCG.2013.130

[22] Robert E. Roth. 2017. Visual variables. In International Encyclopedia of Geography: People, the Earth, Environment and Technology. John Wiley \& Sons, Ltd, Oxford, UK, 1-11. https://doi.org/10.1002/9781118786352.wbieg0761

[23] Pierre-Yves Vandenbussche, Ghislain A. Atemezing, María Poveda-Villalón, and Bernard Vatant. 2016. Linked Open Vocabularies (LOV): a gateway to reusable semantic vocabularies on the Web. Semantic Web 8, 3 (dec 2016), 437-452. https: //doi.org/10.3233/SW-160213

[24] Annika Wolff, Daniel Gooch, Umar Mir, Jose Cavero, and Gerd Kortuem. 2015. Removing barriers for citizen participation to urban innovation. Digital Cities 9 Workshop (2015).

[25] ChuanTao Yin, Zhang Xiong, Hui Chen, JingYuan Wang, Daven Cooper, and Bertrand David. 2015. A literature survey on smart cities. Science China Information Sciences 58, 10 (oct 2015), 1-18. https://doi.org/10.1007/s11432-015-5397-4 